\title{
Blood pressure measurement in adults: large cuffs for all?
}

Peter R Croft, J Kennedy Cruickshank

\begin{abstract}
Study objective-The aim of the study was to determine whether a single size of cuff for adult blood pressure measurements is appropriate for general clinical practice.

Design-The study was a prospective survey of a sample of adult blood pressure measurements using two cuffs with different bladder sizes $(12 \times 23 \mathrm{~cm}$ and $15 \times 33 \mathrm{~cm}$ ) in a randomised design using a random zero sphygmomanometer.

Setting-Blood pressures were measured in a general practice and in a hospital outpatient clinic.
\end{abstract}

Participants-The participants were 35-60 year old men and women invited to attend a blood pressure screening programme in the general practice $(n=170)$, and 35-74 year old patients attending a general medical outpatients $(\mathrm{n}=72)$.

Measurements and main results-The small cuff gave higher readings of systolic blood pressure than the large cuff (mean difference $4.4 \mathrm{~mm} \mathrm{Hg}$ ). The difference increased as systolic pressure increased but did not show a clear association with arm circumference. The small cuff also gave higher diastolic pressure readings (mean difference $3.0 \mathrm{~mm} \mathrm{Hg}$ ), but only when arm circumference exceeded $30 \mathrm{~cm}$. The variability of the differences between readings from the two cuffs was wide, little affected by arm circumference, and was similar to the variability between measurements using the same cuff size.

Conclusions-In terms of precision there

Industrial and Community Health Research Centre, Department of Postgraduate Medicine, University of Keele, Stoke-onTrent, Staffordshire ST5 SBG, United

Kingdom

P R Croft

Department of

Medicine, Northwick

Park Hospital/Clinica

Research Centre,

Harrow, United

Kingdom

J K Cruickshank

Correspondence to: Dr Croft, at ARC Centre, Stopford Building Centre, Stopford Building (University of Manchester) M13 9PT, United Kingdom

Accepted for publication November 1989 is no basis for using two different cuff sizes unless it is physically difficult to obtain a reading with one or the other. Since readings with large cuffs are closer to intraarterial pressures in large arms, and the large cuff used here did not underestimate diastolic pressure in small arms, the large cuff alone could be recommended for general use.

The British Hypertension Society concluded in 1986 that the size of sphygmomanometer cuff bladder available as "standard" adult is too small for satisfactory measurement of blood pressure in most adult arms. Their general recommendations for the appropriate size were that the bladder length should be $80 \%$ of the arm circumference, and the width at least $40 \% .{ }^{1}$ These same criteria were proposed originally in the report by the American Heart Association in $1951,{ }^{2}$ and survived two subsequent revisions of the report. $^{34}$

Although some studies of cuff size in relation to arm circumference have concluded that the standard size is adequate for general use, ${ }^{5}$ most have agreed with the conclusions of the British Hypertension Society report. Proposed solutions have been more controversial. The American Heart Association list of correct but mostly unavailable bladder sizes, and the suggested use of correction factors by others, ${ }^{6}$ are both based on the assumption that there is an ideal specification for each arm size, and that many different cuff sizes or an adjustment to each reading is the solution.

However, the traditional specifications do not represent an "ideal' but rather a minimum appropriate size. Some authorities, including the British Hypertension Society, have recommended that larger cuffs be more generally available, perhaps by scaling up both the length and the width of the standard cuff bladder. These recommendations are based on the notion that the large cuff is closer to the "truth". Studies which have compared intra-arterial readings with indirect cuff measurements have generally found that in people with large arms, the larger cuff sizes do give readings closer to the direct records. ${ }^{7-10}$ Although only one study ${ }^{11}$ has produced evidence that direct measurements are better predictors of morbid outcomes than indirect, such intraarterial recordings are the nearest we come to a blood pressure standard. Little attention has been given to the variability of readings from available cuffs and to the way this is influenced by arm circumference and height of blood pressure.

The current study examines whether the use of a single large cuff would be appropriate for general clinical practice. We have compared blood pressure readings in a wide range of individuals using two currently available adult cuff sizes. The aims were first to estimate the effect of cuff size on blood pressure recordings at different arm circumferences, and then to set that estimate in the context of the repeatability of blood pressure measurements.

\section{Methods}

There were two sources of subjects studied, a group general practice in the Potteries and a hospital outpatients in north west London. Patients in the group practice had participated in a blood pressure screening programme for two years. Blood pressure, weight and height were measured during screening by the practice nurse, who had been trained to use a Hawksley random zero sphygmomanometer with the cuffs described below. All 35-60 year old men and women on the 
practice age-sex register had been invited, with a $75 \%$ response. $^{12}$ Subjects for the present study were sampled randomly from this group within strata of body mass index to ensure a range of arm circumferences. They were invited by letter to reattend and $70 \%$ did so. The second group were aged 35-74 years and attended general medical outpatient clinics in north west London.

CUFF SIZES

The smaller cuff, supplied as "standard adult" with most hospital and general practice surgery sphygmomanometers, had a bladder $12 \mathrm{~cm}$ wide $\times 23 \mathrm{~cm}$ long. The large adult size, recommended currently and arbitrarily in the "Baumanometer" range for arms larger than $33 \mathrm{~cm}$ circumference, measured $15 \mathrm{~cm}$ wide $\times 33 \mathrm{~cm}$ long. These two cuffs are referred to in this report as "small" and "large" respectively.

\section{RANDOMISATION}

Each subject was randomly allocated to have their first blood pressure reading with either of the two cuff sizes, subsequent readings then alternating with the other. All readings were taken after sitting for at least five minutes, using diastolic phase $V$, with a random zero machine either by PRC (Stoke) or JKC (London). All subjects had three readings, the first one discarded initially as "habituation" and the second and third used to compare variability of single records. One hundred and four of the subjects then took part in a study of repeatability of each cuff size in which four values were recorded, again with the initial cuff size randomly allocated.

\section{ANALYSIS}

The method outlined by Bland and Altman ${ }^{13} 14$ for the comparison of two methods of measurement was applied. The first question to be examined was whether a systematically higher measure of blood pressure occurs when a small rather than a large cuff is used over a wide range of arm circumferences. To estimate this, overall means of within individual differences together with their $95 \%$ confidence intervals (CI) were calculated.

Variability and repeatability within individuals can be described by the $95^{\circ}{ }_{0}$ limits of agreement: ${ }^{1314}$ within person differences between repeated measurements are expressed as a range between two standard deviations below to two standard deviations above the mean of the differences. The ranges obtained from two small cuff readings, two large cuff readings, and a single small and a single large cuff reading were calculated and compared.

\section{Results}

Of 242 patients recruited, 170 were from general practice and 72 from outpatient clinics. Of these, 120 were randomised to have a small cuff blood pressure reading first, and 122 to a reading with the large cuff first (table I). The results from five patients were discarded because arrhythmias made an adequate blood pressure reading impossible.

The means of the differences between small and large cuff readings, calculated by subtracting the
Table I Arm circumference and blood pressure $(\mathrm{mm}$ $\mathrm{Hg}$ ) in 237 subjects

\begin{tabular}{lrrc}
\hline & Mean & \multicolumn{1}{c}{ SD } & Range \\
\hline Arm circumference (cm) & $31 \cdot 3$ & $4 \cdot 1$ & $20-47$ \\
SBP small & $141 \cdot 4$ & 21.7 & $99-214$ \\
SBP large & $137 \cdot 1$ & 20.4 & $86-200$ \\
DBP small & 86.8 & 12.0 & $56-124$ \\
DBP large & 83.9 & 12.0 & $48-128$ \\
\hline
\end{tabular}

$\overline{\mathrm{SBP}}=$ systolic blood pressure; $\mathrm{DBP}=$ diastolic blood pressure

large from the small cuff reading, irrespective of the order in which they were taken, were for systolic blood pressure $4.4 \mathrm{~mm} \mathrm{Hg}\left(95^{\circ}{ }_{0} \mathrm{CI}\right.$ $3 \cdot 1-5 \cdot 7)$ and for diastolic blood pressure $3.0 \mathrm{~mm}$ $\mathrm{Hg}\left(95^{\circ}{ }_{\mathrm{o}} \mathrm{CI} 2 \cdot 6-3 \cdot 4\right)$. The means of the small cuff measurements were higher in both cases (table II).

ARM CIRCUMFERENCE, BLOOD PRESSURE AND CUFF SIZE

When the differences between measurements from the two cuffs were stratified by tertiles of arm circumference (table II), the small cuff gave higher mean readings of systolic blood pressure in all three arm circumference categories and of diastolic blood pressure in the upper two categories. There was no overall difference between the diastolic blood pressure measurements from each cuff in arms of $30 \mathrm{~cm}$ circumference or less.

The influence of the actual height of blood pressure was examined by plotting the mean blood pressure from each pair of cuff readings against arm circumference and against the difference between the cuff readings. The mean of the systolic blood pressure taken with small and large cuffs rose with arm circumference (regression coefficient for arm circumference $\left.=1 \cdot 65,95^{\circ} \circ \mathrm{CI} 1 \cdot 02-2 \cdot 28\right)$, as did diastolic blood pressure (regression coefficient $=1.07,95^{\circ}$ o CI $\left.0.74-1 \cdot 40\right)$. The difference between systolic pressure readings taken with the two cuffs tended to increase as mean systolic pressure increased (regression coefficient for systolic blood pressure difference $=0.07,95^{\circ}$ o CI $0.01-0.12$ ), but there was no evidence of a similar relationship for diastolic pressure. This influence of the height of mean systolic pressure on the difference between the two readings was independent of the association of systolic pressure and arm circumference.

\section{CUFF ORDER}

Any order effect in the large-small comparison was assumed to be removed by the randomisation of cuff order. Replicate measurements using the same cuff size revealed a systematic order effect. There were statistically significant mean differences between first and second readings of systolic blood pressure for both the small cuff $\left(3.4 \mathrm{~mm} \mathrm{Hg}, 95^{\circ}, \mathrm{CI} 1.5-5.3\right)$ and the large cuff $\left(4.7 \mathrm{~mm} \mathrm{Hg}, 95^{\circ}{ }^{\circ} \mathrm{CI} 2 \cdot 8-6 \cdot 6\right)$. In the case of diastolic blood pressure, an order effect in the opposite direction (second reading higher than the first) emerged for the mean difference between small cuff readings $\left(-2.0 \mathrm{~mm} \mathrm{Hg}, 95^{\prime \prime}\right.$ " $\mathrm{CI}-3.4$ to -0.6 ) but there was no effect when using the large cuff $\left(-0.1 \mathrm{~mm} \mathrm{Hg}, 95^{\circ}{ }^{\circ} \mathrm{CI}-1.4\right.$ to $+1 \cdot 2)$. 
Table II Bं Blood pressure differences between small and large cuff readings, for total group and by tertiles of arm circumference

\begin{tabular}{|c|c|c|c|c|}
\hline \multirow[t]{2}{*}{ Total group } & & \multicolumn{3}{|c|}{ Arm circumference $(\mathrm{cm})$} \\
\hline & & $\leqslant 30$ & $30 \cdot 5$ & $33-$ \\
\hline Number & 237 & 79 & 82 & 76 \\
\hline $\begin{array}{l}\text { SBP difference } \\
\text { Mean (SD) } \\
95 \% \text { confidence interval }\end{array}$ & $\begin{array}{l}4.4(10 \cdot 0) \\
3 \cdot 1-5 \cdot 7\end{array}$ & $\begin{array}{l}3 \cdot 3(9 \cdot 1) \\
1 \cdot 3-5 \cdot 3\end{array}$ & $\begin{array}{l}3.9(11.7) \\
1.4-6.4\end{array}$ & $\begin{array}{l}6 \cdot 1(8 \cdot 6) \\
4 \cdot 2-8 \cdot 0\end{array}$ \\
\hline $\begin{array}{l}\text { DBP difference } \\
\text { Mean (SD) } \\
95 \% \text { confidence interval }\end{array}$ & $\begin{array}{l}3.0(7 \cdot 2) \\
2.6-3.4\end{array}$ & $\begin{array}{r}0.8(7 \cdot 1) \\
-0.8-2 \cdot 4\end{array}$ & $\begin{array}{l}3.5(7.6) \\
1.9-5.1\end{array}$ & $\begin{array}{l}4 \cdot 8(6 \cdot 1) \\
3 \cdot 4-6 \cdot 2\end{array}$ \\
\hline
\end{tabular}

SBP = systolic blood pressure; $\mathrm{DBP}=$ diastolic blood pressure; $\mathrm{BP}$ differences = small cuff minus large cuff $(\mathrm{mm} \mathrm{Hg})$

\section{VARIA B I L I T Y}

The $95 \%$ limits of agreement between paired readings using each of the three possible cuff size combinations were not symmetrical about zero because of the systematic effects discussed above (table III). The ranges were of similar magnitude for both systolic and diastolic pressure whether identical or different cuff sizes were used for the two readings.

Table III The limits of agreement between repeated $B P$ measurements for three cuff combinations ( $\mathrm{mm} \mathrm{Hg}$ )

\begin{tabular}{llcr}
\hline $\begin{array}{l}95 \% \text { limits of } \\
\text { agreement }\end{array}$ & Small & Large & Small-large \\
\hline SBP & -14.5 to 23.9 & -16.2 to 23.0 & -15.6 to 24.4 \\
DBP & -16.0 to 12.0 & -13.7 to 13.9 & -11.8 to 17.8
\end{tabular}

SBP = systolic blood pressure; $\mathrm{DBP}=$ diastolic blood pressure

Scatterplots were drawn of the differences between cuff readings and the means of each pair of readings. The range of differences between small and large cuff readings became wider with increasing systolic pressure. So both the size of the systolic pressure difference and its variability tended to increase with the height of the systolic pressure. No association of variability with increasing mean diastolic pressure or with arm circumference was apparent.

\section{Discussion}

In this study the "standard adult" size of sphygmomanometer cuff gave higher readings of blood pressure than a commercially available large cuff. Systolic blood pressure was a mean 4. $4 \mathrm{~mm} \mathrm{Hg}$ higher when the small cuff was used. There was a tendency for this difference to increase with arm size, but the change was not significant over the range of arm circumferences usually encountered in clinical practice.

The mean difference between diastolic pressure readings from small and large cuffs was $3.0 \mathrm{~mm}$ $\mathrm{Hg}$ but this varied clearly with arm circumference. The finding that there was no overall difference between diastolic pressure readings from the two cuffs in arms of $30 \mathrm{~cm}$ circumference or less casts doubt on the notion that blood pressure will be underestimated when large cuffs are used on thin people. ${ }^{6}$

In the case of systolic blood pressure the height of the pressure was a more important influence on the size of the mean difference between cuff readings than was arm circumference. Cuff size may be more important to the systolic pressure measurement at those pressures which begin to matter in treatment decisions.
These conclusions are about the overall effect of cuff size on blood pressure measurement. They are of less importance to individual blood pressure measurements. In this study the $95 \%$ limits of agreement between readings with a large and a "standard adult" size cuff were $-15.6 \mathrm{~mm} \mathrm{Hg}$ to $+24.4 \mathrm{~mm} \mathrm{Hg}$ for systolic pressure, and $-11.8 \mathrm{~mm} \mathrm{Hg}$ to $17.8 \mathrm{~mm} \mathrm{Hg}$ for diastolic pressure. These were similar to the $95 \%$ ranges of repeatability for each cuff size separately. This variability appeared unaffected by the arm circumference or by the height of the diastolic pressure, although there was some association with the height of the systolic pressure. This means that as clinical measuring instruments of blood pressure over a wide range of arm sizes and blood pressures the two cuff sizes were of comparable precision.

The conclusion is that if a reading from a larger cuff is accepted as nearer to the "true" blood pressure with increasing arm circumference-a reasonable assumption from intra-arterial studies-then the large adult cuff employed in this study can be used in all situations except where the practicalities of measurement require a smaller cuff.

The limits of agreement illustrate the wide variability of blood pressure readings, a feature often obscured by summary statistics. The implication is that recording the mean of two readings is the clinically most appropriate method of monitoring blood pressure. The British Hypertension Society report estimated that between one third and one half of all adults have an arm circumference of $30 \mathrm{~cm}$ or more. Many people would have a potentially more appropriate blood pressure measurement if a large cuff were used, and the evidence here suggests that such a policy would not result in thinner people having a less appropriate recording. A recent paper which addressed rather different issues with direct arterial pressure recordings reached a similar conclusion, namely that the large rectangular cuff $(14 \times 38 \mathrm{~cm}$ in their study) should be the single size of choice for routine use. ${ }^{15}$ An earlier study had reached the same conclusion with a $14.5 \times 37 \mathrm{~cm}$ cuff. $^{16}$ Yet there is evidence that large cuffs are not being used because many practices and hospitals either do not stock them or use the standard cuff exclusively. ${ }^{17} \mathrm{~A}$ change in the national habit would seem more likely if a single cuff could be recommended in most situations, rather than evoking policies of duplicate cuffs, special cuff designs, ${ }^{18}$ or complex adjustments to the readings.

If the effect observed here of using large cuffs were translated in national terms to all adults, it might affect the chance of embarking on therapy for many thousands of mild hypertensives. As an example we can use figures from the Renfrew study, ${ }^{19}$ in which $10 \%$ of adults aged 45 to 64 years were found to have a diastolic blood pressure of $95-99 \mathrm{~mm} \mathrm{Hg}$ with a $12 \times 22 \mathrm{~cm}$ cuff. We will assume that $40 \%$ of this group had an arm circumference of $30 \mathrm{~cm}$ or more, and that their mean diastolic pressure would fall by about $4 \mathrm{~mm}$ $\mathrm{Hg}$ if a large cuff were used. If a diastolic pressure of $95 \mathrm{~mm} \mathrm{Hg}$ or more were an indication for intervention, then some $3 \%$ of adults in this age group would be reclassified from the treatment 
category to a diastolic pressure of less than $95 \mathrm{~mm}$ $\mathrm{Hg}$. This represents approximately 300000 adults in England and Wales. The variability of individual blood pressure measurements would be unaffected by a switch to large cuffs, although this variability could be reduced if the mean of two readings became the recording norm.

What should the precise dimensions of a new standard cuff be? The British Hypertension Society authors recommend a $35 \mathrm{~cm}$ length, without committing themselves to a single width specification. In our study we used a $15 \times 33 \mathrm{~cm}$ size and found occasional difficulty in fitting this on to smaller arms. It is commercially available and so our conclusion would be a new standard size of $15 \times 33 \mathrm{~cm}$, with a smaller cuff available if measurement is impractical.

PRC held a grant from the West Midlands Regional Research Committee. We thank Doctors I C McManus and $M$ Collins for help with earlier drafts, and $\mathrm{Mr} \mathrm{D}$ Altman for his helpful comments; Nurse Christine Harrison, the doctors, staff and patients of Palmerston Street Surgery; and Louise Ellis for the typescript.

1 Petrie JC, O'Brien ET, Littler WA, DeSwiet M. British Hypertension Society recommendations on blood pressure measurement. Br Med $\mathcal{F} 1986 ; 293: 611-5$.

2 Committee to revise standardisation of high blood pressure readings: recommendations for human blood pressure determinations by sphygmomanometers. New York American Heart Association, 1951.

3 American Heart Association. Recommendations for human blood pressure determination by sphygmomanometers. Circulation 1967; 36: 980-8.
4 American Heart Association. Recommendations for human blood pressure determination by sphygmomanometers. Circulation 1980; 62: 114-55A.

5 Burch GE, Shewey L. Sphygmomanometric cuff size and Burch GE, Shewey L. Sphygmomanometric cuff size

6 blood pressure recordings. fैAMA 1973; 225: 1215-8.

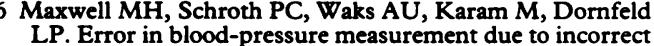
LP. Error in blood-pressure measurement due to in

7 Nielsen PE, Janniche H. The accuracy of auscultatory measurement of arm blood pressure in very obese subjects. Acta Med Scand 1974; 195: 403-9.

8 Karvonen MJ, Telivuo LJ, Jarvinen EJK Sphygmomanometer cuff size and accuracy of indirect blood pressure measurement. Am $\mathcal{f}$ Cardiol 1964; 13: 668-93.

9 King GE. Errors in clinical measurement of blood pressure in obesity. Clin Sci 1967; 32: 223-37.

10 Nielsen PE, Larsen B, Holstein P, Poulsen HL. Accuracy of auscultatory blood pressure measurements in hypertensive and obese subjects. Hypertension 1983; 5: 122-7.

11 Floras JS, Hassan MO, Sever PS, Jones JV, Osikowska B, Sleight $P$. Cuff and ambulatory blood pressure in subjects with essential hypertension. Lancet 1981 ; ii: 107-9.

12 Croft PR, Brigg D, Smith S, Harrison C, Collins M, Branthwaite A. How useful is weight reduction in the management of hypertension? F $R$ Coll Gen Pract 1986; 36 445-8.

13 Altman DG, Bland JM. Letter to the Editor. $f$ Epidemiol Community Health 1986; 40: 274-5.

14 Bland JM, Altman DG. Statistical methods for assessing agreement between two methods of clinical measurement. Lancet 1986; i: 307-10.

15 Van Montfrans GA, Van Der Hoeven GMA, Karemaker JM, Wieling W, Dunning AJ. Accuracy of auscultatory blood pressure measurement with a long cuff. $\mathrm{Br} M e d-$ 1987; 295: 354-5.

16 Linfors EW, Feussner JR, Blessing CL, Starmer F, Neelon FA, McKee PA. Spurious hypertension in the obese patient. Arch Int Med 1984; 144: 1482-5.

17 Burke MJ, Towers HM, O'Malley K, Fitzgerald DJ, O'Brien ET. Sphygmomanometers in hospital and family practice: problems and recommendations. $\mathrm{Br}$ Med $\mathcal{f} 1982$, 285: 469-71.

18 Maxwell GF, Pruijt JFM, Arntzenius AC. Comparison of the conical cuff and the standard rectangular cuffs. Int $\mathcal{J}$ Epidemiol 1985; 14: 468-72.

19 Hawthorne VM, Greaves DA, Beevers DG. Blood pressure in a Scottish town. $B r$ Med $\mathcal{F} 1974$; iii: 600-3. 